\title{
Research on the Cultivation Mode of Postgraduates' Scientific Research Ability in the New Situation
}

\author{
Fengbin Liu \\ College of physical education \\ Dalian University \\ Dalian, China, 116622
}

\begin{abstract}
The level of postgraduate research is an important index to measure the quality of postgraduate education. It is the key to cultivate graduate students' innovation ability and directly affects the quality of graduate education in our country. In this paper, we use the current situation of the research ability training of sports professional graduate students in our country as the breakthrough point, and analyze systematically the forms of postgraduate scientific research, degree thesis level, teaching content and mode and other aspects. According to the actual situation of graduate education in our college, we focus on the training program and curriculum system of graduates, construct preliminarily the framework of the innovative cultivation mode of sports postgraduates with the hope that we can explore a new way of thinking and provide some new methods for the cultivation of innovative ability of sports postgraduates in China.
\end{abstract}

Keywords-postgraduates; scientific research ability; sports specialty; training mode

\section{INTRODUCTION}

Scientific research is one of the important functions of modern universities. It is not only an important source of social innovation, but also the key to cultivate the innovative ability. It is of great significance to cultivate graduate students innovative scientific research ability and to improve the quality of graduate education by organizing graduate students to carry out the scientific research activities scientifically and reasonably. The research ability of postgraduates can not only directly affect our country's scientific and technological innovation abilities and scientific research level, but also it is an important index to measure the quality of graduate education in our country.

In recent years, with the expansion of graduate students and the instructor team, there are some problems in the process of graduate education: such as the decrease quality of education, the overlook the training of postgraduate research ability, the lack of innovative thesis topics, the lack of innovative topics in thesis, the decline in the quality of papers and other issues. All of these make the quality of graduate education in the signs of decline [1,2].Based on the actual situation of sports scientific research, we investigate and do some research on the problems existing in the cultivation of postgraduate scientific research ability, discuss how to cultivate and improve the level of scientific research and innovation ability of postgraduates, and put forward some feasible countermeasures and suggestions for your reference.

\section{ANALYSIS OF THE CUlTIVATION OF PostgRAdUATE SCIENTIFIC RESEARCH ABILITY IN CURRENT SITUATION IN CHINA}

\section{A. Forms of Postgraduate Scientific Research}

Scientific research is an important way to cultivate organizational ability, coordination ability, social interaction ability, discovering and solving problems, and innovating ability for graduate students. Generally speaking, the graduate students are engaged in three forms of scientific research[3,4]: First, the graduate students participate in the research of their instructors. Under the guidance of the instructors, they will get some cultivations and training in scientific research, and become a member of the research team. The proportion of students is close to $20 \%$; Second, the instructors will recommend the research topics, the topics will be a wide range, but have a certain cutting-edge, especially in the humanities and sociology research. The proportion of students is around 35\%; Third, the students will choose the research topics as they like, graduate students identify research topics and apply for the research issues by themselves. The instructors will give some guidance, however, students can play a full personal specialties.

At present, the research issues of sports are less, the research topics which were chosen by students are in majority $(60 \%)$. Moreover, the guidance from the instructors are not in the right place. The topics are lack of new ideas and the research methods are out of date. No matter which form we choose in the area of scientific research and training for postgraduate students, the participation of research subjects and the abilities which be engaged in the scientific research are both very important. Only by combining the two aspects together, can we cultivate the scientific research abilities of the graduate students smoothly and better.

\section{B. Analysis of Thesis Level}

The graduate degree thesis is the best embodiment of postgraduates' scientific research ability, which can reflect graduate students' scientific research ability synthetically. The research group randomly selected the theses of graduate 
students in five domestic normal universities and a sports college for this subject. We randomly selected 100 degree theses from 2010 to 2015 in these six universities, synthesized the evaluation for the experts, and analyzed the existing problems. The following major problems are common in the writing of graduate degree thesis: problem consciousness is not strong, the students are not good at finding out problems; the thesis writing is not in standard; They only apply and repeat other method Simply and mechanically; They only reveal the surface phenomenon, but do not study the internal relations deeply; they only do the simple extension, and further confirm the work of others; they only use a certain experiment to confirm the known conclusions and so on.

\section{Analysis of Teaching Content and Mode}

The teaching of degree courses is the foundation of the cultivation in graduate students' scientific research ability. The aim of the teaching in degree course is to impart knowledge, to inspire ideas, to explore new ways of thinking and to form the initial capacity. In order to achieve good teaching effects in the graduate degree course, it depends on two key factors: one is the content of the degree course, and the other is the teaching mode. Whether or not the content of the degree course can reflect the dynamic and theoretical frontier of the subject in time, and whether or not the teaching mode can motivate the enthusiasm of the graduate students, they all directly play an important role in the realization of the purpose in classroom teaching.

The current sports graduate degree courses have the following problems [5-7]: On one hand, the coverage of teaching content is too narrow. Many majors in some sports colleges only focus on the knowledge content of the major itself. They rarely involve or do not involve the interdisciplinary content at all, and they do not broaden the field and research direction of professional study. On the other hand, the old teaching methods have been used, teachers are mostly using the traditional teaching mode, they will not effectively improve the teaching effectiveness and will not cultivate graduate students' research ability. Graduate teaching should focus on the teaching in the research, and the curriculum should reflect the objective and orientation of graduate education. It will provide the graduate students a solid theoretical foundation and the necessary technology foreshadowing by setting the reasonable research courses and doing some thematic research.

\section{THE CONSTRUCTION FRAMEWORK OF GRADUATE STUDENT INNOVATION TRAINING MODE}

The aim of graduate student teaching is to carry out research activities. To strengthen the cultivation of postgraduates' innovative ability should be the fundamental task of postgraduate education, also the innovation ability is the fundamental symbol of the quality in postgraduate education. To cultivate innovation ability will go through the following ways [8-10]: First, we need a reasonable knowledge structure. It is necessary not only to grasp the basic theory, but also to master the systematic expertise theory; Second, the training of innovation ability needs the comprehensive ability and image thinking. The scientific innovation requires a skeptical spirit, out of the traditional knowledge system, and the challenge of the original knowledge; Third, the cultivation of innovation ability requires the combination of science education and humanistic education, the essence of quality education is innovation. Innovation is a spiritual state, a value trend and a scientific method. Therefore, the cultivation of postgraduates is a way of research rather than a teaching method. It is a quality education way which integrates the science and humanities and focus on the cultivation of innovative ability

There is no unified model for postgraduate research innovation. The training patterns of foreign countries vary widely, and so do in China. In our country, it is impossible and unnecessary to copy foreign models, also it should not be different from the other countries [11-13]. All the colleges in China should have its own characteristics and follow its own path to create the innovation ability in the graduate students' cultivation according to the situation in China and in its own school.

With the increase and adjustment of the discipline specialty in our college and the development trend of higher education in the future, it is necessary to adjust and redesign the training program to make it more scientific and standardized.

We reconstructed the graduate student's training plan and the curriculum system establishment according to the actual situation of postgraduate training. So that it will solve some problems in the reform of the graduate course system and training program, accelerate the deep and multi-faceted reform of postgraduate education in our university and improve the quality of postgraduate training. With the hope that can we find a new practical exploration for the cultivation of the innovative ability of sports postgraduates in our country.

\section{A. Training Programs and Curriculum Objectives and Principles}

Modularization of disciplinary platform: Graduate program should be in accordance with a discipline and discipline group to build, and strive to reflect the "widecaliber, thick foundation" training high-level talent.

Training process characteristics: training program should highlight and reflect the different disciplines in personnel training in the "characteristics", "personalized", "differentiation", while the new training program should have a strong operational and flexible.

Knowledge and ability integration: handle correctly the relationship between "knowledge" and "ability", determine the "knowledge" as a means to "capacity" as the goal, solve the "knowledge" and "capacity" convergence and rational distribution.

Curriculum system integration: In accordance with the new discipline training platform, graduate students in the Institute of Physical Education will choose four subjects out of six disciplines group. There are humanities and social 
sciences, professional basic theory, professional skills and information technology. We will build a new postgraduate training curriculum system, highlight the integrity of the PE curriculum system according to the requirements of high, new and fine.

\section{B. Training Program and the Specific Content of the Curriculum System}

1) Course system and capability: Establish the postgraduate education curriculum system will base on the mode of "wide caliber, thick foundation, high ability" and "undergraduate and master integration", which emphasizes the "system and coordination" of curriculum system.

Highlight and increase the construction of core professional courses, professional graduate teaching materials and quality courses. Just do it as a means to start the reform in the comprehensive professional core curriculum teaching.

Start the reform in the curriculum assessment and assessment methods, use the curriculum standardization examination in the implementation of basic courses, take the separation of teaching and examination; Adopt the open examination method and means in specialized courses in the combinative way of the knowledge and ability, quantitative and qualitative. So that it will stimulate and encourage the students' creative thinking and flexibility in the learning process; For the professional courses, pay more attention to the proportion among the basic theory, professional core, professional elective and cross-edge courses, and organize more special reports and presentations, increase a large number of extra-curricular reading at the same time.

2) Course setting: The graduate curriculum system consists of three modules: Basic courses: University offers the political, language, foreign language classes and other types of large-scale platform for basic courses, each subject group can offer the elective courses respectively; Professional courses: including professional core classes, professional elective courses, the use the mode of $1+3+1$, that is, one university course group, three professional courses, one professional skills courses and other elective courses; Comprehensive courses: humanities and social sciences, scientific research methods, innovation and entrepreneurship courses.

3) Scientific research quality and innovation ability: Scientific research quality and innovation ability are very important aspects in cultivating postgraduates' independent thinking, flexible using of knowledge, innovation consciousness and scientific research. On the part of literature reading, graduate students themselves have to write 2-4 million words of the sports literature review report, the amount of literature reading are not less than 50, the amount of foreign literature reading are not less than $50 \%$, and the instructors will be responsible for the final scores. The innovative ability will be selected by the students themselves according to their comprehensive quality conditions and the nature of their major. It will include academic papers publication, social practice, independent research, scientific research achievement award, extracurricular work design, invention ability and so on. The college teaching committee will be responsible to identify and evaluate.

\section{CONCLUSION}

The cultivation of graduate research and innovation ability is not only the objective need of adapting to the modernization construction of our country, but also the need of cultivating new talents to adapt to the social development. It is the guiding ideology of curriculum that we need combine the teaching and scientific research to cultivate graduate research and innovation ability. Graduate scientific research is the continuation and deepening of the teaching process, and it is also a scientific education method and management mode for innovative talents. Only by strengthening the reform of the graduate curriculum system and putting the research and innovation as a target to construct a new way of cultivating graduate students, can we improve the students' innovation ability, enhance their exploration consciousness and scientific research ability and cultivate the complex sports professional senior personnel with the spirit of innovation and scientific research practice.

\section{REFERENCES}

[1] Qianhua Fang, Hansheng Huang and Guilin Zhu,Predicament and path for physical professional degree education of full-time postgraduates in china, Journal of Shanghai University of Sports. vol.38, no.6, pp.79-83, 2014.

[2] Liang Zhen, Jun Kang and Shuang Ying, The reform path of model construction of postgraduate education in China, Degree and Graduate Education, no.1, pp.14-18, 2013.

[3] Qijia YU, A Study on the mode and operational mechanism of industry-university-research cooperative education, East China normal university graduate thesis, 4,2011 .

[4] Ruilin Zhang, Researchon the evaluation system of the training quality for master students in physical education, Journal of Shanghai University of Sports. vol.34, no.4, pp.25-29, 2010.

[5] Ruilin Zhang, Research on the types and characteristics of cultivation model for the sports master degree candidate in China in the New Era, Journal of Sports and Science, vol.31, no.3, pp.95-98, 2010.

[6] Mengxia Niu, Research on the education of full-time master of science in physical Education professional graduate students, Central China Normal University graduate thesis,5,2013.

[7] Limin Yao and Limin Zhu, The investigation of postgraduate cultivation, Journal of Higher Education, vol.34, no.11, pp.55-59, 2013.

[8] Feilong Zuo, Study on postgraduate training programs from the perspective of the relationship between supply and demand of sports master, Suzhou University graduate thesis,3,2015.

[9] Lin Sun and Ming Yin, The cultivation of postgraduate creative ability, Course Education Research, no.8, pp.26-27, 2012.

[10] Jian Wang and Lupin Qu, Research on Building the Quality Evaluation Index System of China's Full-time Sport Masters Cultivation, Journal of Beijing Sport University, vol.35, no.10, pp.7680, 2012.

[11] Hongyan Guo and Zhijun Fang, The examining and thinking on the Cultivation of the Physical Education Postgraduates with the View of PCK, Degree and Graduate Education, no.7, pp.26-29, 2015. 
[12] Zhonghua Huang and Xuejun Du, The cultivation mode of postgraduate in Cambridge University and the enlightenment, Management and Administration,no.12, pp.150-153, 2015.

[13] Qing Lu, Jun Yi, Lin Cong, et al. A comparative study on the cultivation of sports postgraduates in Japan, UK, Russia and Germany, Journal of Sports Culture Guide, no.5, pp.96-100, 2010. 